[Agr. Biol. Chem., Vol. 36, No. 6, p. 1043 1044, 1972]

\title{
PMR Study on the Absolute Structure of Kanamycins and Related Compounds ${ }^{\dagger}$
}

\author{
By Akira Hasegawa, ${ }^{*}$ Daikichi Nishimura \\ and Minoru NAKAJIMA \\ Department of Agricultural Chemistry, College of Agriculture, \\ Kyoto University, Kyoto \\ * Department of Agricultural Chemistry, College of Agriculture, \\ Gifu University, Gifu \\ Received November 8, 1971
}

In this paper, we wish to report a simple empirical rule to determine linkage positions in the 2-deoxystreptamine component with sugars in amino sugar antibiotics such as kanamycins, neomycins and paromomycins.

The PMR spectra of $\mathrm{N}$-acetyl derivatives of kanamycins and related compounds show a signal of anomeric proton of sugars at $4.62 \sim$ 4.72: (in $\mathrm{D}_{2} \mathrm{O}$ ) when sugars are linked in the $\alpha$-form at $\mathrm{C}_{4}$ position of $\mathrm{N}, \mathrm{N}^{\prime}$-diacetyl-2deoxystreptamine (DSTA), while at 4.86 4.95- (in $\mathrm{D}_{2} \mathrm{O}$ ) when linked at $\mathrm{C}_{6}$ position (Table I. No. 1 12).

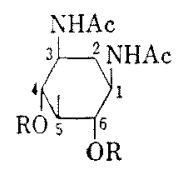

DSTA

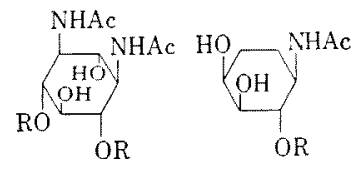

STA

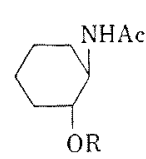

$\mathrm{AD}$
R: Sugar moiety

Comparing with the absolute configuration of kanamycin $\mathrm{A}$ which was determined by $\mathrm{X}$-ray analysis, ${ }^{1 \prime}$ the pmr spectrum of tetra- $\mathrm{N}$-acetylkanamycin A suggests that 1) the anomeric proton of 6-acetamido-6-deoxy-D-glucose moiety at the $\mathrm{C}_{4}$ position is much closer to the plane

T Synthetic Studies on Carbohydrate Antibiotics, Part XI. Part X, K. Kitahara, S. Takahashi, H. Shibata, N. Eurihara and M. Nakajima, Agr. Biol. Chem., 33, 748 (1969).
Table I. The PMR Data of Anomeric Proton Signals of $\alpha$-GLYCOSIDES OF AMINOCYClitols.

\begin{tabular}{|c|c|c|c|}
\hline No. & Compoundar & \multicolumn{2}{|c|}{$\begin{array}{c}\text { Anomeric protons: } \\
\tau(J=\mathrm{cps})\end{array}$} \\
\hline 1 & $6-\mathrm{AG}(4)-\mathrm{DST} A$ & $4.66(3.0)$ & \\
\hline 2 & $3-\mathrm{AG}(4)-\mathrm{DST} A$ & $4.70(3.0)$ & \\
\hline 3 & 2-AG(4)-DSTA & $4.63(3.3)$ & \\
\hline 4 & $2,6-\mathrm{AG}(4)-\mathrm{DST} A$ & $4.62(3.0)$ & \\
\hline 5 & $6-\mathrm{AG}(6)-\mathrm{DST} A$ & & $4.93(3.5)$ \\
\hline 6 & 3-AG(6)-DSTA & & $4.90(3.5)$ \\
\hline 7 & 2-AG $(6)-D S T A$ & & $4.87(3.0)$ \\
\hline 8 & 6-AG(4)-DSTA-3-AG(6) & $4.65(3.0)$ & $4.86(4.0)$ \\
\hline 9 & $2,6-\mathrm{AG}(4)-\mathrm{DST} A-3-\mathrm{AG}(6)$ & $4.62(3.5)$ & $4.87(3.5)$ \\
\hline 10 & 2-AG(4)-DSTA-3-AG(6) & $4.62(3.0)$ & $4.87(3.5)$ \\
\hline 11 & 3-AG(4)-DSTA-6-AG(6) & $4.70(3.0)$ & $4.95(3.5)$ \\
\hline 12 & $3-\mathrm{AG}(4)-\mathrm{DST} A-2-\mathrm{AG}(6)$ & $4.72(2.0)$ & $4.88(1.5)$ \\
\hline 13 & MN-DSTA & $4.72(1.0)$ & $4.89(1.0)$ \\
\hline 14 & GL-DSTA & $4.65(3.0)$ & $4.90(3.0)$ \\
\hline 15 & 2-AG-DC & $4.70(3.0)$ & $4.88(3.5)$ \\
\hline 16 & 2-AG(4)-STA & $4.62(3.0)$ & \\
\hline 17 & $2-\mathrm{AG}(6)-\mathrm{STA}$ & & $4.88(3.5)$ \\
\hline 18 & $2-\mathrm{AG}-\mathrm{AC}(+)$ & \multicolumn{2}{|c|}{$5.01(3.5)$} \\
\hline 19 & $2-\mathrm{AG}-\mathrm{AC}(-)$ & \multicolumn{2}{|c|}{$4.99(3.0)$} \\
\hline
\end{tabular}

a) Abbreviations are as follows: $6-\mathrm{AG}$ : 6-acetamido6-deoxy-a-D-glucopyranosyl, 3-AG: 3-acetamido-3deoxy- $\alpha$-D-glucopyranosyl, 2,6-AG: 2,6-diacetamido2,6-dideoxy- $\alpha$-D-glucopyranosyl, MN: $\alpha$-D-mannopyranosyl, GL: a-D-glucopyranosyl, DSTA: $N, N^{\prime}-$ diacetyl-2-deoxystreptamine, STA: N, N'-diacetylstreptamine, DC: N-acetyl-( \pm -dihydroconduramine F-4, AC: N-acetyl-(+)-\{or (-)-\}2-aminocyclohexanol. (These amino-cyclitols are shown in Fig. 1.) For example, 6-AG(4)-DSTA: N, N'-diacetyl-4-0-(6-acetamido-6-deoxy - $\alpha$-D-glucopyranosyl) - 2 -deoxystreptamine. The number in parenthesis indicates the linkage position of sugar in DSTA or STA. The compounds (No. 13 15) are diastereomeric mixture. 
of $\mathrm{N}$-acetyl carbonyl group of DSTA than that of 3-acetamido-3-deoxy-D-glucose moiety at the $\mathrm{C}_{6}$ position, and 2) the free rotation of glycosidic linkage is more hindered at $\mathrm{C}_{4}$ than at $\mathrm{C}_{6}$ by non-bonded interactions between DSTA and sugar moiety.

Accordingly, the signal of anomeric proton of the sugar at $\mathrm{C}_{4}$ shifts to a lower magnetic field by an anisotropy ${ }^{21}$ of the $\mathrm{N}$-acetyl carbonyl group of DSTA, provided that the steric structures of the acetyl derivatives of kanamycin $\mathrm{A}$ and related compounds in $\mathrm{D}_{2} \mathrm{O}$ are similar to that of kanamycin A determined by X-ray analysis.

In the case of $\alpha$-glycosides having two sugar components at $\mathrm{C}_{4}$ and $\mathrm{C}_{6}$ of DSTA like kanamycins, the signals of anomeric protons appeared independently at the corresponding regions, and the same phenomena were also observed in the mixture of two diastereomers (No. 13 15). The same principle can be applied to the $\alpha$-glycosides of $N, N^{\prime}$-diacetylstreptamine (No. 16, 17).

In N-acetyl-2-aminocyclohexanol, the difference in the chemical shift of anomeric protons of $\alpha$-glycosides between ( + -)(No. 18) and (-)-isomer (No. 19) is very little since the free rotation of glycosidic linkage is not hindered.

This empirical rule can be applied to determine the absolute configuration of 2deoxystreptamine derivatives and analogs together with conventionally used techniques such as Reeves' cuprammonium method. ${ }^{3 !}$

We thank the people in the Central Res. Lab. of Sankyo Co. Ltd. who kindly presented several kinds of samples. We wish to thank Dr. Tetsuro Shingu and Miss Mitsuko Okawa of the College of Pharmacy and Miss Shigeko Yamashita of the Department of Food Science and Technology for pmr measurements.

\section{REFERENCES}

1) G. Koyama and Y. Iitaka, Tetrahedron Letters, $1968,1875$.

2) L. M. Jackman, "Applications of NMR Spectroscopy in Organic Chemistry," Pergamon Press, London, 1959, pp. 122 124.

3) M. Hichens and K. L. Rinehart, Jr., J. Am. Chem. Soc., 85, 1547 (1963); S. Umezawa, K. Tatsuta and T. Tsuchiya, Bull. Chem. Soc, Japan, 39, 1244 (1966). 